\title{
MUSEUS E VIRTUALIDADES: UMA RELAÇÃO PARA O SÉCULO XXI
}

\author{
MUSEOS Y VIRTUALIDAD: UNA RELACIÓN PARA EL \\ SIGLO XXI
}

\author{
Fábio Rogério Batista Lima * \\ Plácida Leopoldina Ventura Amorim da Costa Santos** \\ Julio Bittencourt Francisco***
}

\section{RESUMO:}

Introdução: Antes da reprodução fotográfica, a apreciação da arte era limitada apenas às visitas físicas aos museus ou as coleções pessoais. Com a digitalização e a transposição de obras de arte para plataformas museológicas digitais cria-se simulacros das obras originais, e sua forma material e orgânica transforma-se em linguagem computacional de bits e bytes.

Objetivo: Identificar as características que indicam as transformações da estrutura de apresentação da obra de arte na sua passagem para ambientes virtuais quando digitalizadas, uma vez que a mudança de um sistema semiótico para outro ocasiona rupturas e mutações na qualidade estética da obra de arte produzida sobre um suporte e transferida para outro.

Metodologia: Com uso do método bibliográfico descritivo, verificaram-se as características de acesso à informação através das novas plataformas museológicas no ambiente Web.

Resultados: Com as plataformas digitais on-line, os museus perdem em intensidade, pois as obras expostas são representações das originais, no entanto, ganham em extensividade, pois democratizam o acesso.

Conclusões: Essas plataformas recontextualizam as obras e servem como guia e tradutor do acervo, levando o indivíduo a percorrer a exposição com um conjunto de informações que atuam como apoio didático-pedagógico no processo de aquisição de repertório e ampliação da base de conhecimento.

Palavras-chave: Museu Virtual. Imagem. Informação e Tecnologia. Intersemioses Digitais. Plataformas digitais. Museus de arte. Google Art Project.

\footnotetext{
* Mestre em Ciência da Informação e doutorando no Programa de Pós-Graduação em Ciência da Informação da Universidade Estadual Paulista Júlio de Mesquita Filho - Campus de Marília, Brasil. fabio.robal@yahoo.com.br.

**Doutora em Linguística pela Universidade de São Paulo, Brasil. Docente do Programa de Pós-Graduação em Ciência da Informação da Universidade Estadual Paulista Júlio de Mesquita Filho - Campus de Marília, Brasil. E-mail: placida@marilia.unesp.br

*** Mestre em Memória Social e Documento (UNIRIO) Doutorando em História da América Latina (PUCRS) e professor de Museologia na FABICO/UFRGS. francisjulio@hotmail.com
} 
Fábio Rogério Batista Lima, Plácida Leopoldina Ventura Amorim da Costa Santos, Julio Bittencourt Francisco

Museus e virtualidades: uma relação para o século XXI

\section{INTRODUÇÃO}

Refletir sobre a atualidade é também enfatizar questões importantes referentes à arte, à ciência e à tecnologia, o que nos remete a questões como globalização, crescimento informacional, velocidade e virtualidade, situações relacionadas à evolução do homem e sua Teknè. O homem, enquanto agente dessa evolução, tem como uma de suas atividades a arte, uma manifestação de ordem estética resultante da percepção, das emoções e das ideias, a partir da utilização de uma grande variedade de meios e materiais, como a pintura, a escrita, a música, a dança, a fotografia, a escultura, entre outros.

A arte influenciou a ciência e foi por ela também muito influenciada. Entretanto, na contemporaneidade, é a ciência, juntamente com a tecnologia, que vem imprimindo significativamente suas marcas sobre a arte. Os "[...] materiais e métodos podem ser diferentes, mas as estimulações cruzadas são frequentes e férteis para a arte, a ciência e a tecnologia." (CZEGLEDY, 2003, p. 126).

Desde o surgimento das principais sociedades primitivas, passando pelas complexas cidades pós-industriais até os dias atuais, o homem descobriu como fazer o fogo, cultivou a terra, domesticou os animais, construiu cidades, dominou os recursos energéticos naturais, implementou indústrias, conquistou o espaço cósmico, viajou pelos confins do espaço-tempo, e "[...] durante esse trajeto a tecnologia ganhou significações e representações diversas em um movimento de vai e vem com a vida social”. (LEMOS, 2008, p. 25).

De acordo com Pinho (2008, p. 8), tudo o que é humano é ao mesmo tempo psíquico, técnico, histórico etc. e se integra com o que o autor chama de "equipamentos coletivos de subjetivação", como, por exemplo, as novas tecnologias informáticas e a Internet. Com esses aparatos tecnológicos, a história da comunicação entre os homens, bem como as construções de imagens e suas particularidades históricas e culturais, mudaram e continuam em constante transformação. Antes da reprodução fotográfica, a apreciação da arte era limitada apenas às visitas físicas aos museus ou as coleções pessoais. 
Fábio Rogério Batista Lima, Plácida Leopoldina Ventura Amorim da Costa Santos, Julio Bittencourt Francisco

Museus e virtualidades: uma relação para o século XXI

Com a digitalização e a transposição de obras de arte para plataformas museológicas digitais criam-se simulacros das obras originais, e sua forma material e orgânica transforma-se em linguagem computacional de bits e bytes, e a forma de acesso às obras musealizadas também sofrem transformações.

Nesse contexto, a proposta deste estudo é demonstrar as características das novas plataformas museológicas para o acesso as artes no ambiente da Web e identificar as características que indicam as transformações da estrutura de apresentação da obra de arte do museu tradicional para a plataforma digital na Web, uma vez que a mudança de um sistema semiótico para outro ocasiona rupturas e mutações na qualidade estética da obra de arte produzida sobre um suporte e transferida para outro. Pois, considerando a informação como o conhecimento inscrito em um suporte (BUCKLAND et al., 1991; LE COADIC, 2004), segundo Rodrigues e Crippa (2009, p. 8) "não há como não observar a obra de arte como tal inscrição. Dessa forma, essa informação torna-se passível de ser tratada pelo profissional da informação".

\section{IMAGEM: uma síntese histórica}

Desde o princípio, o ser humano tem a necessidade de se comunicar com os seus semelhantes, e os meios utilizados para esse processo têm variado ao longo dos séculos. A linguagem, definida como produção e entendimento da fala, se desenvolveu com a evolução da espécie humana. A fala humana poderia ser comparada à comunicação entre outros animais, porém a linguagem humana tem elementos que a distinguem da linguagem dos animais, na medida em que possui criatividade e interpretação.

No início, quando os primeiros homens, Homo Herectus (que viveram entre 1,8 milhões de anos e 300.000 anos atrás), habitavam a Terra, o centro de sua fala não era muito desenvolvida e a comunicação se dava por meio de grunhidos, rosnadas e gestos. Na época dos Neandertais (há cerca de 300.000 anos até aproximadamente 29.000 anos). Com o Homo Sapiens (há 200.000 anos), o cérebro se desenvolveu e propiciou o desenvolvimento da fala. Foi um período caracterizado pela linguagem. No processo de comunicação, o papel 
Fábio Rogério Batista Lima, Plácida Leopoldina Ventura Amorim da Costa Santos, Julio Bittencourt Francisco

Museus e virtualidades: uma relação para o século XXI

da linguagem é primordial, pois "[...] ela garante o intercâmbio da significação, mediando as relações entre pessoas, flexibilizando o pensamento e ampliando a capacidade conceitual e proposicional de cada indivíduo" (BARRETO, 2008, p. 114).

Acredita-se que esse desenvolvimento se deu pelo convívio simultâneo das duas culturas diferentes, Neandertais e Homo Sapiens, e pela necessidade da comunicação entre eles. Assim, outras formas de linguagens surgiram como, por exemplo, as imagens, que eram

[...] sempre modeladas por estruturas profundas, ligadas ao exercício de uma linguagem, assim como a vinculação a uma organização simbólica (a uma cultura, a uma sociedade); mas a imagem também é um meio de comunicação e de representação do mundo, que tem seu lugar em todas as sociedades humanas. (AUMONT, 1993, p. 131).

Tais imagens, encontradas em sua maioria em paredes de cavernas, como as de Altamira e Lascaux, conhecidas como pinturas rupestres, eram feitas com o uso de sangue de animais, argila e seiva de plantas. Acredita-se que as sociedades primitivas se expressavam principalmente por meio dessas pinturas.

Os meios técnicos que suportam a informação têm uma relação com o espaço e com o tempo da vida social. De acordo com Barreto (1999, não paginado), os "homens, ao produzirem as teias de significações para si mesmos, empregam meios técnicos/suportes materiais para transmitir as formas simbólicas". E assim, ainda segundo o autor eles "fundamentam sua vida social nos aspectos da produção, armazenamento e circulação da informação e conteúdo simbólico".

A grande variedade de pinturas rupestres, feitas por povos diferentes e em locais diferentes, mantém algumas características comuns na representação do cotidiano, de ferramentas, de armas, ou figuras que representavam situações específicas, como a caça, a dança, o sexo, entre 
Fábio Rogério Batista Lima, Plácida Leopoldina Ventura Amorim da Costa Santos, Julio Bittencourt Francisco

Museus e virtualidades: uma relação para o século XXI

outras. Embora muitas vezes as cenas de caça representadas em cavernas não descrevam uma situação vivida pelo grupo, elas possuem um caráter mágico, preparando o grupo para essa tarefa que lhes garantia a sobrevivência.

Com o passar do tempo, a produção de imagens começou a ser feita por meio da utilização de variados tipos de materiais e suportes, mas ainda com o mesmo intuito: comunicar, representar e informar. Na modernidade, os modos de produção de imagem romperam definitivamente com os modos anteriores. O desenvolvimento de aparatos técnicos e químicos para a produção de imagem possibilitou a captura de imagens do mundo real de modo muito mais rápido. Exemplo disso é a fotografia, definida por Aumont (1993, p. 164) como "[...] ação da luz sobre certas substâncias que assim levadas a reagir quimicamente, são chamadas fotossensíveis. Uma superfície fotossensível exposta à luz será transformada provisória ou permanentemente [...]".

A fotografia impulsionou o crescimento do uso da imagem para variados fins. Diferentemente da pintura, a fotografia passou a servir como documento comprobatório e indicial. A maneira de produzir imagens por máquinas fotográficas evoluiu com o passar do tempo e hoje temos à disposição, de modo muito acessível, máquinas digitais para a captura e produção instantânea de imagens. Tal perspectiva nos leva a concordar com as reflexões do cientista norte-americano Negroponte (1995), quando diz que vivemos em um meio onde a tendência de nossas atividades de trabalho, nossos entretenimentos, nossas histórias e relações com outras pessoas tornam-se cada vez mais dependentes das tecnologias digitais. As imagens produzidas atualmente, na maioria das vezes, ilustram essa reflexão, pois, percebemos que elas estão sendo produzidas cada vez mais com uso de equipamentos eletrônicos, seja por câmeras digitais, por aparelhos celulares, por tablets ou mesmo por computadores portáteis com câmeras embutidas.

O quadro 1 ilustra a evolução da imagem ao longo do tempo e o efeito que ela exerce sobre a sociedade e a cultura a que pertence. 
Fábio Rogério Batista Lima, Plácida Leopoldina Ventura Amorim da Costa Santos, Julio Bittencourt Francisco

Museus e virtualidades: uma relação para o século XXI

QUADRO 1: Natureza da imagem, papel do receptor

\begin{tabular}{|c|c|c|}
\hline \multicolumn{3}{|c|}{ NATUREZA DA IMAGEM } \\
\hline PRÉ & FOTOGRÁFICA & Pós \\
\hline $\begin{array}{lllll}\text { Figurar } & 0 & \text { visível } & \text { e } & \text { o } \\
\text { invisível } & & & & \end{array}$ & Registrar o visível & Visualizar o modelável \\
\hline Figurar por imitação & Capturar por conexão & $\begin{array}{l}\text { Simular por variações de } \\
\text { parâmetros }\end{array}$ \\
\hline Imagem espelho & Imagem documento & Imagem matriz \\
\hline \multicolumn{3}{|c|}{ PAPEL DO RECEPTOR } \\
\hline PRÉ & FOTOGRÁFICA & Pós \\
\hline Contemplação & Observação & Interação \\
\hline Nostalgia & Reconhecimento & Imersão \\
\hline Aura & Identificação & Navegação \\
\hline
\end{tabular}

Fonte: Adaptação de Santaella (2001, p. 172-178)

As imagens hoje estão em todos os lugares: em placas de trânsito, outdoors, vitrines, bancas de jornal, logomarcas de empresas, impressas na pele das pessoas como tatuagens, nas fachadas dos prédios como grafite, nos muros da cidade como pichação ou em livros, revistas e massivamente na rede Internet. De acordo com Aumont (1993, p. 314),

As imagens, isso é inegável, há mais de 100 anos multiplicamse quantitativamente em proporções impressionantes e sempre 
Fábio Rogério Batista Lima, Plácida Leopoldina Ventura Amorim da Costa Santos, Julio Bittencourt Francisco

Museus e virtualidades: uma relação para o século XXI

crescentes. Além disso, percebemos que essas imagens invadem nossa vida cotidiana, que seu fluxo não pode ser contido.

Isso se dá devido às facilidades que temos na conexão entre computador e scanners, com os instrumentos de captura e restituição da imagem, e no progresso das interfaces de uso. Com a fotografia, a videoarte, o cinema e, principalmente, com a inserção de equipamentos informáticos na construção de obras digitais e também nos ambientes virtuais, como nos webmuseus, foi possível confeccionar uma nova proposta plástica recorrendo aos programas computacionais. É no ambiente Web que está ocorrendo a fusão de linguagens e onde a arte agora está imersa. Segundo Eirin de Rapp (2000, p. 44), essa fusão "[...] se reflete nas páginas de arte, nas quais a informação estética é complementada por música, animação, conexões para outras páginas [...]", num fluxo intersemiótico que aguça novas percepções cognitivas.

As percepções cognitivas, estimuladas pelas possibilidades oferecidas no ciberespaço, nos encaminharam para uma reflexão sobre as intersemioses digitais. Entretanto, não há como falar de intersemioses digitais sem antes nos remetermos à semiótica e à apresentação de seu conceito. O estudo semiótico tem por objeto os signos e investiga todas as linguagens possíveis, como, por exemplo, a linguagem oral (fala), a linguagem textual (textos), a linguagem corporal (gestos), a linguagem visual (imagens), dentre outras, "no exame dos modos de constituição de todo e qualquer fenômeno de produção de significação e sentido" (SANTAELLA, 1983, p. 13).

A semiótica, do grego semeiotiké, é a ciência que estuda o processo de articulação e produção de sentido entre os diversos tipos de códigos e linguagens. Tem por objetivo "estabelecer como devem ser todos os signos para uma inteligência capaz de apreender através da experiência [...]" (SILVEIRA, 2007, p. 38). Ocupa-se do estudo do processo de significação ou representação, na natureza e na cultura, dos conceitos e das ideias. Em uma acepção geral a "semiótica é a teoria de todos os tipos de signos, códigos, sinais e linguagens. Portanto, ela nos permite compreender palavras, imagens, 
Fábio Rogério Batista Lima, Plácida Leopoldina Ventura Amorim da Costa Santos, Julio Bittencourt Francisco

Museus e virtualidades: uma relação para o século XXI

sons em todas as suas dimensões e tipos de manifestações" (SANTAELA, 2010, p.59). A intersemiose, por sua vez, consiste:

[...] na interpretação dos signos verbais por meio de sistemas de signos não verbais', ou 'de um sistema de signo para outro, por exemplo, da arte verbal para a música, a dança, o cinema ou a pintura, ou vice-versa [...] (PLAZA, 2008, p. XI).

O processo tradutor intersemiótico, entretanto, é influenciado tanto pelos variados tipos de linguagem (sonora, visual, digital etc.), quanto pelo meio empregado na tradução de uma linguagem/mídia para a outra, por exemplo, por meio da transformação da fotografia em filme (meio cinematográfico), ocorrendo mudanças na forma de linguagem e no suporte. No entanto, ambos deixam a marca da história em seus processos e solicitam outra sintaxe e outro modo de formar sentido.

O espaço de exposição das obras na tela do computador via Internet permite que o usuário navegue contemplando as obras - muitas vezes com imagens em movimento. Ao mesmo tempo em que ouve um fundo musical, visualiza os catálogos das obras expostas e a biografia dos artistas. Esse espaço, com textos e imagens, possibilita ao visitante assistir a vídeos com as entrevistas dos curadores comentando as exposições, ou até mesmo com os próprios artistas falando sobre as obras ou a corrente artística de que fazem parte.

As tecnologias de manipulação de imagens e os novos ambientes virtuais para sua hospedagem, como os webmuseus e as galerias virtuais, acarretaram mudanças em nosso sistema cognitivo de percepção e recepção de informações imagéticas, "[...] criando quadros de memórias, fornecendo os símbolos e o ambiente mental, requeridos para determinados momentos de ruptura decisivos para a reestruturação dos sistemas da cultura" (JORENTE, 2009, p. 105). Segundo Grau (2007, p.16), "[...] arte e ciência, mais uma vez, aliam-se a serviço dos métodos mais complexos de produção de imagens [...]." O mundo imagético ao nosso redor vem se transformando muito rapidamente. 
Fábio Rogério Batista Lima, Plácida Leopoldina Ventura Amorim da Costa Santos, Julio Bittencourt Francisco

Museus e virtualidades: uma relação para o século XXI

Ao mesmo tempo, presenciamos as várias formas de imagens e suas formas de produção pelas novas mídias, que exercem forte impacto sobre a teoria da imagem, teoria da cor e da arte como um todo, influenciando também nos ambientes onde as obras são expostas, como o caso dos museus.

\section{A WEB COMO UMA NOVA PLATAFORMA MUSEOLÓGICA}

Nos últimos anos sites como Tumblr ${ }^{1}$, Blogger ${ }^{2}$ DeviantArt $^{3}$, dentre outros, não só servem como plataformas que permitem aos usuários a troca de idéias e informações, mas também viabilizam a postagem de fotos e documentações sobre obras de arte.

Com o potencial de copiar imagens de sites, os usuários podem anexar documentação de obras de arte, de qualquer época, ao lado de uma outra já postada. Blogueiros podem postar ou se apropriar de peças tão díspares como pianos de cauda, estátuas equestres da antiguidade clássica e readymades dadaísticos, criando uma imagem única, que de outra forma seria impossível viabilizar fisicamente. Estas exposições on-line ecoam as idéias progressistas apresentadas por Malraux (1967, p. 12), que previu que um 'museu sem muros' pode vir a ser infinitamente mais revelador para atualizar nossas memórias do que as grandes obras de arte que os maiores museus poderiam reunir.

Antes da reprodução fotográfica, a apreciação da arte era limitada apenas às visitas físicas aos museus ou as coleções pessoais. Para Malraux, 0 museu sem muros, possibilitaria a qualquer um visualizar qualquer obra de arte, a qualquer hora, em qualquer lugar. Para ele, a melhor maneira de testemunhar a narrativa da história da arte não seria em uma galeria de arte,

\footnotetext{
${ }^{1}$ https://pt.wikipedia.org/wiki/Tumblr

${ }^{2}$ https://pt.wikipedia.org/wiki/Blogger

${ }^{3}$ https://pt.wikipedia.org/wiki/DeviantART
} 
Fábio Rogério Batista Lima, Plácida Leopoldina Ventura Amorim da Costa Santos, Julio Bittencourt Francisco

Museus e virtualidades: uma relação para o século XXI

mas no museu sem muros. Hoje, o Google Art Project oferecem exatamente o que Malraux havia pretendido.

\subsection{Google Art Project}

O Google Art Project é uma ferramenta do Google com colaboração de diversos museus espalhados pelo mundo a qual permite a visita a museus e seus catálogos através da plataforma Web. Criado em 2011, começou com os acervos do Alte Nationalgalerie e Gemäldegalerie, em Berlim; Freer Gallery of Art, em Washington; The Frick Collection, The Metropolitan Museum of Art e MoMA, em Nova York; Galeria Uffizi, em Florença; National Gallery eTate Modern, em Londres; Museu Reina Sofia e Museu Thyssen, em Madri; Palácio de Versalhes, na França; Museu Kampa, em Praga; Museu Van Gogh e Rijksmuseum, em Amsterdã; Museu Estatal Hermitage, em São Petersburgo; e a Galeria Estatal Tretyakov, em Moscou. Em 3 de abril de 2012, foi lançada a segunda fase do projeto, com o número de acervos digitalizados passando de 17 para 151. A página inicial é apresentada na figura 1.

Figura 1: Pagina inicial do Google Art Project

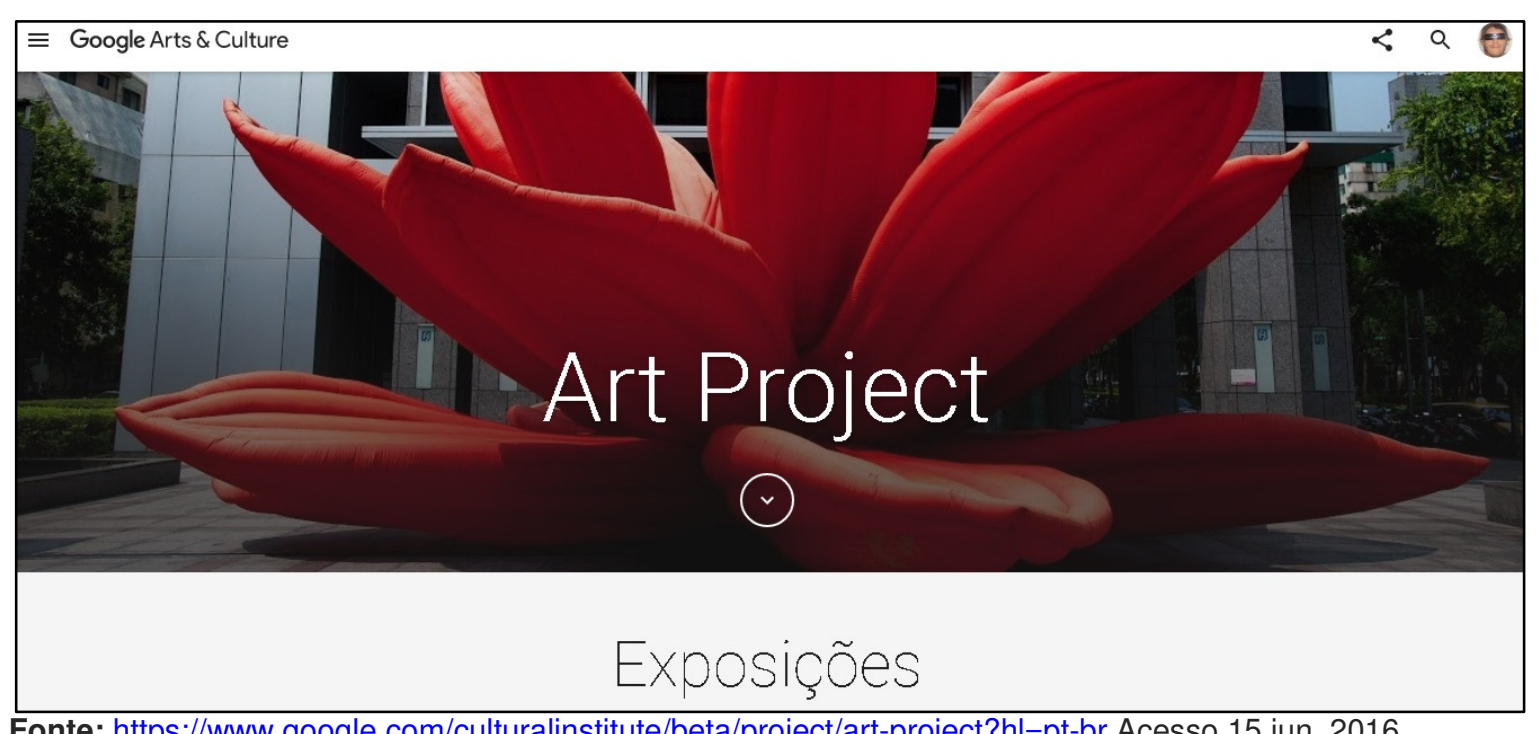

Fonte: https://www.google.com/culturalinstitute/beta/project/art-project?hl=pt-br Acesso 15 jun. 2016

Atualmente são mais de trinta mil obras digitalizadas no acervo de cerca de cento e cinquenta museus em 40 países espalhados pelo mundo. Em 
Fábio Rogério Batista Lima, Plácida Leopoldina Ventura Amorim da Costa Santos, Julio Bittencourt Francisco

Museus e virtualidades: uma relação para o século XXI

reportagem recente escrita pelo colunista da Folha.com, Matheus Magenta, no caderno llustrado do dia três de abril de 2012, diz: o "Brasil acaba de entrar na era virtual da museologia".

O Museu de Arte Moderna MAM-SP, com 88 obras de 85 artistas e a Pinacoteca do Estado de São Paulo com 95 obras de 48 artistas, são os primeiros a participarem do projeto no país. Além da presença do catálogo no site, cada museu escolheu uma obra para ser registrada com tecnologia de alta resolução (7 bilhões de megapixels). Um painel dos grafiteiros 'Os Gêmeos', figura 2, foi escolhido pela direção do MAM-SP para essa experiência.

Figura 2: Painel sem título dos grafiteiros 'Os Gêmeos'

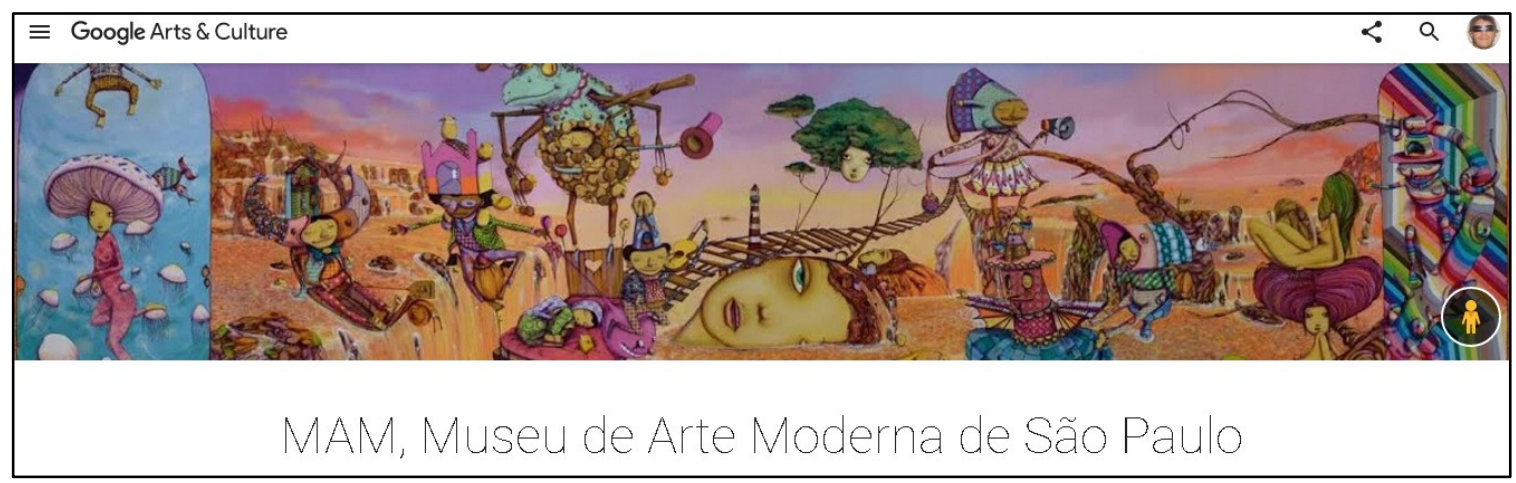

Fonte: https://www.google.com/culturalinstitute/beta/partner/museu-de-arte-moderna-de-saopaulo?hl=pt-br. Acesso em: 15 jun. 2016.

Em entrevista com a Bibliotecária do MAM/SP, Léia Carmen Cassoni ${ }^{4}$, feita pelo autor em julho de 2012:

No momento em que o Google Art Project faz as filmagens no $M A M / S P$, em dezembro de 2011, está ocorrendo a tradicional exposição denominada Panorama da Arte Brasileira, em sua 31. - edição. Essa exposição acontece desde quando houve a instalação do atual prédio no Parque do Ibirapuera em São Paulo, no ano de 1969. É uma exposição significativa porque

\footnotetext{
${ }^{4}$ Léia Carmen Cassoni é Bibliotecária do MAM/SP
} 
Fábio Rogério Batista Lima, Plácida Leopoldina Ventura Amorim da Costa Santos, Julio Bittencourt Francisco

Museus e virtualidades: uma relação para o século XXI

ela começa em 1969, e traz uma série de obras das quais o museu começa a reconstrução de seu acervo. Porém, dentro do Panorama, as obras não são do MAM, e sim dos artistas escolhido pelo curador. No entanto o MAM compra algumas obras do Panorama para compor seu acervo. Essa exposição caminhou anualmente até 1990, quando passa a ser realizada bianualmente. Ou seja, ela é feita no ano que não tem a bienal (CASSONI, 2012, transcrição).

As obras que estavam naquele momento reunidas na exposição temporária quando foram feitas as filmagens, não eram todas exatamente do acervo do MAM/SP, muitas eram dos próprios artistas e foram selecionadas pelos curadores - por empréstimo - e utilizadas com suas devidas autorizações. Diferentemente da Pinacoteca, onde o que está disponível no site da Google é exatamente o que está no acervo do museu e disponível para visitas presenciais. A obra escolhida pela Pinacoteca- SP para ser exibida em alta definição no site foi "Saudade" do pintor Almeida Júnior. Escolhida pelo Curador-Chefe da Pinacoteca, Ivo Mesquita, que a julgou como a obra mais querida do público do museu e por ser um quadro emblemático do que é arte do século XIX no Brasil, sobretudo a arte em São Paulo e o gosto estético paulista.

A plataforma da Google Art Project possui ferramentas que permitem aos visitantes internautas explorarem tanto as obras dos catálogos (usando o nome dos artistas, país de origem, museus e período histórico da peça) - com informações multimídias dos artistas presentes, bem como dar acesso aos diversos museus espalhados pelo mundo através de visitas virtuais (acesso remoto). O serviço já está integrado ao Google Plus e também às redes sociais como o Facebook.

Na figura 3 é apresentado um detalhe da obra escolhida pela Pinacoteca do Estado de São Paulo com o uso de uma ferramenta do Google Art Project, que possibilita a visualização de detalhes da obra por meio de zoom de até 200 por cento, com qualidade na nitidez. 
Fábio Rogério Batista Lima, Plácida Leopoldina Ventura Amorim da Costa Santos, Julio Bittencourt Francisco

Museus e virtualidades: uma relação para o século XXI

Figura 3 - Quadro "Saudades" no Google Art Project em alta resolução

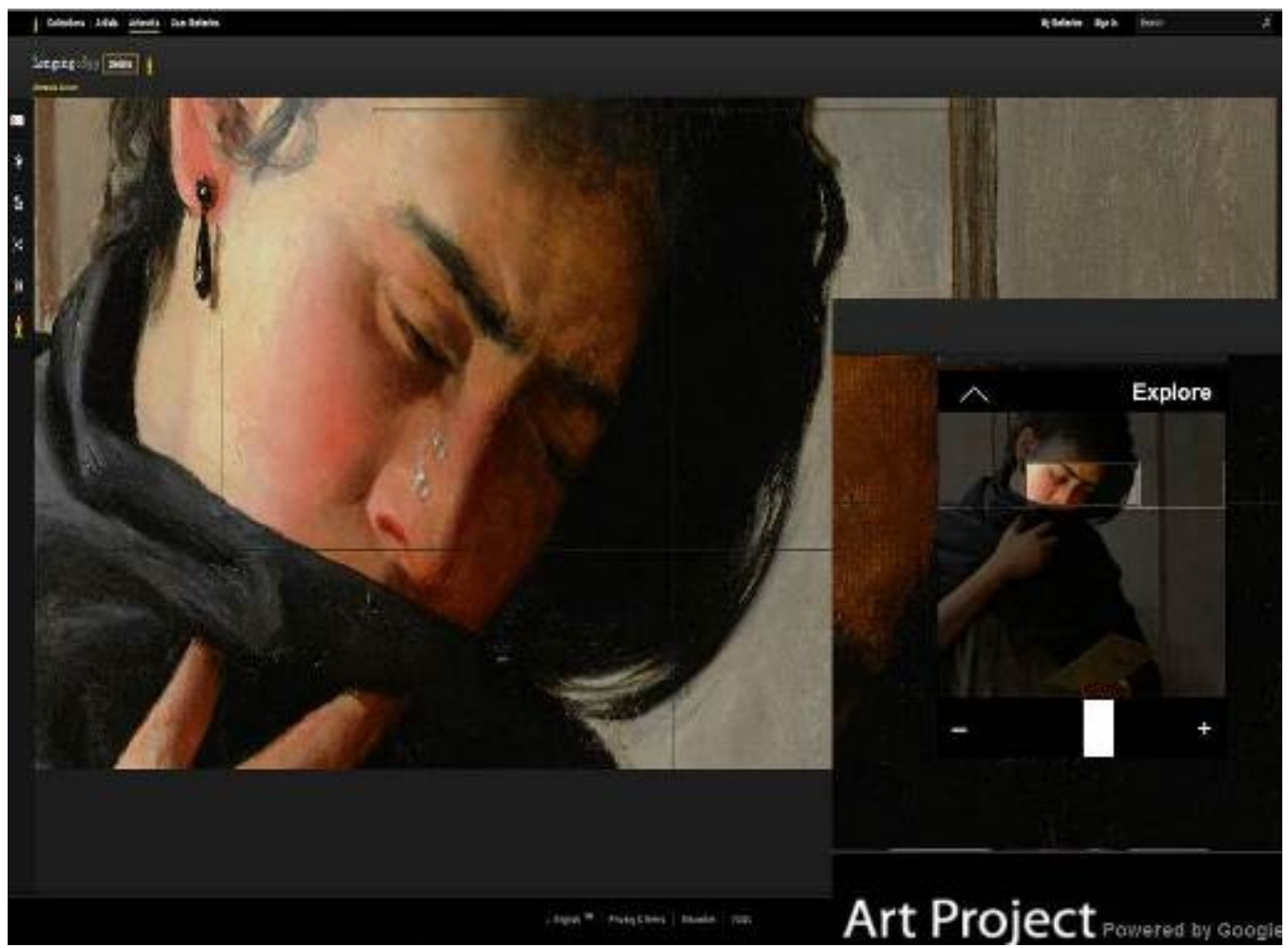

Fonte: Googleartproject.com

Para o atual diretor da Pinacoteca, Marcelo Araújo, publicado na reportagem da Folha.com, o que atraiu a instituição ao projeto da Google foi a ampliação do acesso público ao acervo. Ele afirma que: "[...] não o vejo como um projeto com interesse financeiro. O acervo pertence à população e é importante ampliar todos os canais de acessibilidade a essas obras" (MAGENTA, 2012). A figura 4 demonstra uma reprodução de uma das salas da Pinacoteca.

Figura 4 - Reprodução da Pinacoteca no Googleartproject.com 
Fábio Rogério Batista Lima, Plácida Leopoldina Ventura Amorim da Costa Santos, Julio Bittencourt Francisco

Museus e virtualidades: uma relação para o século XXI

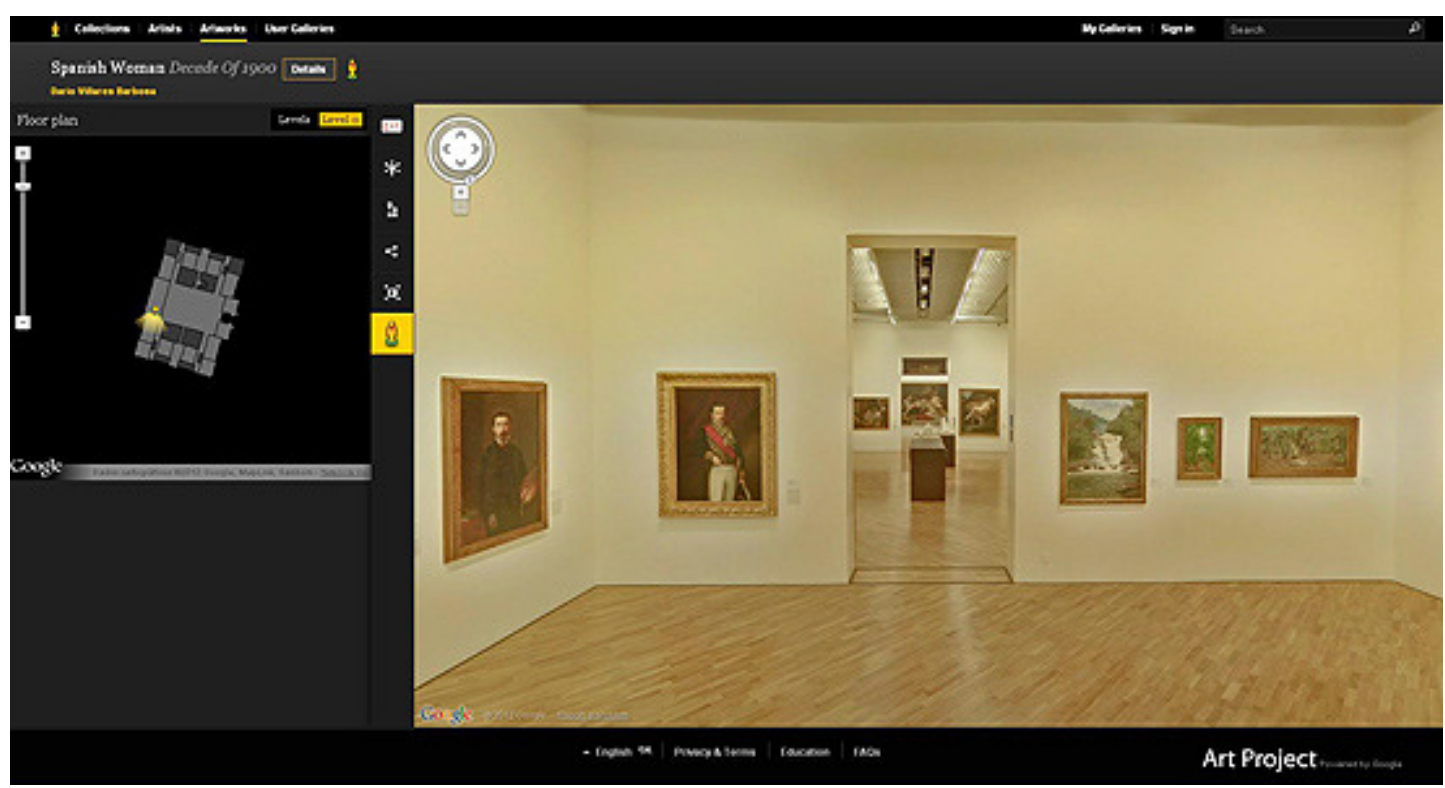

Fonte: Googleartproject.com

Felipe Chaimovich, curador do MAM-SP, na mesma matéria da Folha.com, diz que o acervo do museu já está disponível na página da Internet da própria instituição e também ressalta que a iniciativa além de ampliar o acesso às obras, também reforçará os projetos pedagógicos que já são desenvolvidos pelo museu. Segundo Magenta (2012), "[...] de acordo com o Google Brasil, o contrato entre a empresa e as instituições não envolve dinheiro. A curadoria das obras que são disponibilizadas pelos museus é feita pelas próprias instituições".

Os exemplos nos remeteram a outras reflexões, pois os museus que são criados diretamente em ambiente Web, ou os que possuem acervos transpostos para plataformas digitais, com recursos tecnológicos de criação e manipulação de imagens, não apenas são distintos dos tradicionais museus no que se refere a sua arquitetura, mas também a forma de permitir o acesso a informações das obras.

Quando estamos dentro de um museu presencial (concreto), sentimos a presença do público, dos espaços arquiteturais, da iluminação, dos ruídos, da distância entre um quadro e outro, da variedade de tipos de moldura que cada quadro possui, são características que se perde com qualidade plástica da obra 
Fábio Rogério Batista Lima, Plácida Leopoldina Ventura Amorim da Costa Santos, Julio Bittencourt Francisco

Museus e virtualidades: uma relação para o século XXI

na apresentação em ambientes digitais. Porém, são perdas compensadas, muitas vezes, com ganhos de outras 'qualidades', que não seriam possíveis nos ambientes tradicionais.

Para ilustrar de forma sintética essas transformações apresenta-se o quadro 2. A análise consiste em partir da descrição de seus aspectos compositivos levando em consideração:

Estrutura - ligada ao meio físico, suporte pela qual a obra se materializa.

Forma - diz respeito à presença gestual, caracteristica de cada artista, relacionado ao uso de técnicas, estilos, preferência por determinada paleta de cor, forma pela qual o artista conduz o pincel ao suporte pintado deixando marca de pinceladas, forma com a qual o pintor constroi suas imagens, etc.

Função - relativo à função/papel da obra nos variados tipos de suportes e ambientes que ela esta hospedada e representada, levando em consideração os novos paradigmas tecnológicos e informacionais.

Conteúdo - leva em consideração a forma pela qual a mensagem/conteúdo informacional da obra é transmitida/disseminada para o público (contexto histórico, informações técnicas da obra, etc)

Esses aspectos serão analisados, a fim de estabelecer parâmetros de comparação entre a obra e suas versões: impressa e digital na Web.

Quadro 2: Característica de obras em museu tradicional e em plataforma digital 
Fábio Rogério Batista Lima, Plácida Leopoldina Ventura Amorim da Costa Santos, Julio Bittencourt Francisco

Museus e virtualidades: uma relação para o século XXI

\section{MUSEU TRADICIONAL}

PLATAFORMA DIGITAL-WEB

\begin{tabular}{|c|c|c|}
\hline$\frac{\text { एٓ }}{2}$ & $\begin{array}{lll}\text { Tela } & \text { com } & \text { moldura } \\
\text { fixada } & \text { em } & \text { parede. } \\
\text { Horário e } & \text { lugar do } \\
\text { Museu } & & \end{array}$ & $\begin{array}{l}\text { Plataforma web; suporte digital (bits e } \\
\text { bites). Flexibilidade de horário e lugar }\end{array}$ \\
\hline 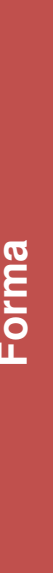 & $\begin{array}{l}\text { Presença gestual do } \\
\text { pintor como (sinais das } \\
\text { pinceladas); linhas, } \\
\text { pontos, cores, texturas, } \\
\text { formas geométricas; } \\
\text { imagem feita com } \\
\text { pigmento orgânico - } \\
\text { tinta }\end{array}$ & $\begin{array}{l}\text { Perda da qualidade gestual como (sinais } \\
\text { das pinceladas); não há textura, mudança } \\
\text { nas cores (formato RGB - Red, Green } \\
\text { and Blue); redução das formas e da } \\
\text { nitidez dos detalhes figurativos da obra }\end{array}$ \\
\hline 욜. & $\begin{array}{l}\text { Contemplativa, } \\
\text { comunicativa, aurática }\end{array}$ & Informativa/simulativa/Interativa \\
\hline 응 & $\begin{array}{l}\text { Plaquetas informativas; } \\
\text { curadores }\end{array}$ & $\begin{array}{l}\text { Imagem e Vídeos; ficha técnica; análise } \\
\text { comentada da obra (contexto histórico); } \\
\text { hiperlinks }\end{array}$ \\
\hline
\end{tabular}

Fonte: Próprio autor.

Dessa forma, ao fazer a reprodução digital de uma obra de arte para um ambiente em suporte digital, há que se levar em consideração as suas transformações. Pois cada material, cada tipo diferente de plataforma dará um efeito diferente na obra, a qual distinguirá da obra original, bem como a forma de interação entre usuários do museu tradicional, no que se refere ao acesso à informação e ao conhecimento referente a arte. 
Fábio Rogério Batista Lima, Plácida Leopoldina Ventura Amorim da Costa Santos, Julio Bittencourt Francisco

Museus e virtualidades: uma relação para o século XXI

Neste sentido, o papel do profissional da informação em conjunto com outros profissionais tanto da área da informática (Designer gráfico) quanto da museologia é estabelecer uma forma de melhora na interface de acesso às obras, garantir a acessibilidade das informações e acesso referente as obras bem como possibilitar uma forma diferente de interatividade e 'experienciação' nessas novas formas de ambientes.

\section{CONSIDERAÇÕES FINAIS}

A revolução digital trouxe uma nova forma de nos interagirmos, pois, transformou a maneira com que as pessoas acessam a informação e se relacionam com os museus,com a arte e com o conhecimento.

Atualmente, os museus são pressionados a modificarem a forma de expor seus acervos por meio do uso de aparatos tecnológicos juntamente com Tecnologias da Informação e Comunicação - TIC, a qual permitem uma nova forma de experiência para os usuários no acesso a informação e entretenimento. Assim, Pois, com as plataformas digitais on-line, os museus perdem em intensidade, pois as obras expostas são representações das originais, no entanto, ganham em 'extensividade', uma vez que democratizam o acesso, 'recontextualizam' as obras e servem como guia e tradutor do acervo, levando o indivíduo a percorrer a exposição com um conjunto de informações que atuam como apoio didático-pedagógico no processo de aquisição de repertório e ampliação da base de conhecimento.

\section{REFERÊNCIAS}

AUMONT, J. A imagem. Campinas: Papirus, 1993.

BARRETO, A. A. Uma quase história da Ciência da Informação. DataGramaZero, Rio de Janeiro, v. 9, n. 2, abr. 2008. Disponível em:

<http://dgz.org.br/ago07/Ind_com.htm>. Acesso em: 28 ago. 2011.

BARRETO, A. A. Os destinos da ciência da informação: entre o cristal e a chama.

DataGramaZero, Rio de Janeiro, n. 0, dez. 1999. Disponível em:

http://www.datagramazero.org.br/dez99/Art_03.htm. Acesso em: 17 nov. 2011.

BUCKLAND, M.; GEY, F. C.; LARSON; R. R. Access to heritage resources using what, where, when, and who. In: TRANT, J., BERMAN, D. (eds.). Museum and the web 
Fábio Rogério Batista Lima, Plácida Leopoldina Ventura Amorim da Costa Santos, Julio Bittencourt Francisco

Museus e virtualidades: uma relação para o século XXI

2007: Proceedings. Toronto: Archives \& Museum Information, 2007. Disponível em: Acesso em 20 mar. 2009.

CZEGLEDY, N. Arte como ciência: ciência como arte. In: DOMINGUES, D. (Org.). Arte e vida no século XXI: tecnologia, ciência e criatividade. São Paulo: UNESP, 2003.

EIRIN DE RAPP, M. N. Web-paginas de arte: informação $X$ arte. In: PINHEIRO, L. V. R.; GONZÁLEZ DE GÓMEZ, M. N. (Org). Interdiscursos da Ciência da Informação: arte, museu e imagem. Rio de Janeiro; Brasília, DF: IBICT/DEP/DDI, 2000. p. 43-58.

JORENTE, M. J. V. Tecnologías, mídias, criação e hipertextualidade na transformação da informação em conhecimento interativo. 2009. 244 f. Tese (Doutorado em Ciência da informação) - Faculdade de Filosofia e Ciência, Universidade Estadual Paulista, Marília, 2009.

LE COADIC, Y. A ciência da informação. 2 ed. rev. amp. Brasília: Briquet de Lemos, 2004.

LEMOS, A. Cibercultura: tecnologia e vida social na cultura contemporânea. Porto Alegre: Sulina, 2008.

MAGENTA, M. Google Art Project libera visita virtual à Pinacoteca e ao MAM.

Folha.com, São Paulo, 3 abr. 2012. Ilustrada. Disponível em:

<http://www1.folha.uol.com.br/ilustrada/1071082-google-art-project-libera-visita-virtuala-pinacoteca-e-ao-mam.shtml>. Acesso em: 3 abr. 2012.

MALRAUX, A. Antimémoires. Galliamard: Paris, 1967

NEGROPONTE, N. A vida digital. Tradução de Sérgio Tellaroli. São Paulo: Companhia das Letras, 1995.

PINHO, J. A. S. As novas tecnologias da informação e comunicação diante da transversalidade entre natureza e cultura. Culturas Midiáticas, Paraíba, Ano I, n. 1, jul./dez., 2008. Disponível em: <

http://www.cchla.ufpb.br/ppgc/smartgc/uploads/arquivos/b29c8438c920100526091245. pdf>. Acesso em: 24 de jun. de 2011.

PLAZA GONZALES, J. Tradução intersemiótica. São Paulo: Perspectiva, 2008.

RODRIGUES, B. C.; CRIPPA, G. A ciência da informação e suas relações com arte e museu de arte. Biblionline, João Pessoa, v. 5, n. 1/2, 2009. Disponível em: <http://www.brapci.inf.br/_repositorio/2010/11/pdf_ce0e96f989_0013065.pdf>.Acesso em: 28 Fev.2016.

SANTAELLA, M. L. O que é semiótica. São Paulo: Brasiliense, 1983. 2001. .; NOTH, W. Imagem: cognição, semiótica e mídia. São Paulo: Iluminuras, Semiótica aplicada. São Paulo: Cengage Learning. 2010. 
Fábio Rogério Batista Lima, Plácida Leopoldina Ventura Amorim da Costa Santos, Julio Bittencourt Francisco

Museus e virtualidades: uma relação para o século XXI

\title{
Title
}

Museums and virtuality: a relationship for the twenty-first century

\begin{abstract}
:
Introduction: Before photograph reproduction, art interaction was limited to physical presence at museums or visiting personal collections. With the digitization and the setup of works of art in digital platforms, museums had created a sort of simulacrum of the original works, but also transforming organic matter into computer language of bits and bytes.
\end{abstract}

Objective: Identify and indicate the artwork on its conversion to virtual world when it passes thru scanned environments, since the change of a semiotic system to another causes disruptions and changes in the aesthetic quality of the work of art produced on a support and moved to another.

Methods: With use of a descriptive literature method in the access of information, new characteristics of access takes place through museological platforms in the web environment.

Results: With the digital online platforms, museums lose in intensity because the exhibited works are but representations of the original, however, it gains in extensiveness as it democratizes access.

Conclusions: These platforms recontextualize the works and serve as a translation guide for the collection. This leads the individual to go through the exhibition with a set of information that acts as didactic and pedagogical support guide in the repertoire of the acquisition process that also help in the expansion of the knowledge base.

Keywords: Virtual Museum. Image. Information and Technology. Digital intersemioses. Digital platforms. Art museums. Google Art Project.

\section{Titulo}

Museos y virtualidad: una relación para el siglo XXI

\section{Resumen:}

Introducción: Antes de la reproducción fotográfica, apreciación del arte se limita sólo a las visitas físicas a los museos y colecciones personales. Con la digitalización y la converción de las obras de arte en plataformas digitales museales se crea una especie de simulacro de la obra original, y su concepción material y orgánico se convierte en lenguaje informático de bits y bytes.

Objetivo: Identificar y indican los cambios en la estructura de la presentación de la obra en su conversión a virtual cuando se escanea entornos, ya que el cambio de un sistema semiótico a otro ocasionan rupturas y cambios en la calidad estética de la obra de arte producida en un soporte que se trasladó a otro.

Metodología: Con el uso del método de la literatura descriptiva, las características del acceso a la información a través de nuevas plataformas museológicas se comproba en el entorno Web. 
Fábio Rogério Batista Lima, Plácida Leopoldina Ventura Amorim da Costa Santos, Julio Bittencourt Francisco

Museus e virtualidades: uma relação para o século XXI

Resultados: Con las plataformas digitales en línea, museos pierden en intensidad porque las obras expuestas son representaciones de la original, sin embargo, también ganan en amplitud como el acceso democratizado.

Conclusiones: Estas plataformas han permitido un cambio de contexto de las obras y actúan como una guía y traductor de la colección, lo que lleva a la persona a ir a través de la exposición con un conjunto de información que sirven de soporte didáctico y pedagógico en el repertorio del proceso de adquisición y expansión de las base de los conocimientos.

Palabras clave: Museo virtual. Imagen. Información y Tecnología. Intersemioses digitales. Plataforma digital. Museo de arte. Google Art Project.

Recebido em: 25.08.2016

Aceito em: 30.11.2016 